\title{
Analysis of Sales Status of the X E-commerce Platform in Beijing
}

\author{
Renhao Jin, Song Han, Li Sun, Sha Wang \\ School of Information, Beijing Wuzi University, Beijing, China
}

Email address

Renhao.jin@outlook.com (Renhao Jin)

\section{To cite this article:}

Renhao Jin, Song Han, Li Sun, Sha Wang. Analysis of Sales Status of the X E-commerce Platform in Beijing. International Journal on Data Science and Technology. Vol. 2, No. 5, 2016, pp. 51-56. doi: 10.11648/j.ijdst.20160205.11

Received: October 5, 2016; Accepted: October 22, 2016; Published: November 21, 2016

\begin{abstract}
In recent years, the development of China electronic commerce is very rapid. More and more people begin to buy necessities and service by internet, which makes online shopping consumption become popular, and different types of e-commerce companies largely arise. This paper focuses on the sales status of a community e-commerce platform, which provides shopping and all kinds of home services. Descriptive analysis and cluster analysis are used to analyze the sale data. The analysis result can be used to modify the strategies of the X platform.
\end{abstract}

Keywords: E-commerce, Community Service, Cluster Analysis

\section{Introduction}

E-commerce is a hot word now and appears in our daily lives. The E-commerce has a lot of types, such as $\mathrm{ABC}, \mathrm{B} 2 \mathrm{C}$, $\mathrm{C} 2 \mathrm{C}, \mathrm{B} 2 \mathrm{~B}, \mathrm{~B} 2 \mathrm{M}, \mathrm{M} 2 \mathrm{C}$ and $\mathrm{O} 2 \mathrm{O}$. The rapid development of this industry closely impacts our society. The e-commerce industries benefit from the development of information technology, and more and more people access the internet by PC or mobile phones. Online shopping is very popular now, which highly promotes the development of electronic commerce. All kinds of e-commerce platforms emerge in an endless stream. The X e-commerce platform is an Online To Offline $(\mathrm{O} 2 \mathrm{O})$ platform, i.e., put the offline service and products trading online. The special aspects of $\mathrm{X}$ e-commerce are that it only runs their business for communities. Now the $\mathrm{X}$ e-commerce is new run company, and they only offer services in several communities in Beijing, and only the residents in these communities can buy in their online platform.

The X e-commerce platform now only offer services in 11 communities, and the trade history data are downloaded from company database. The data includes everyday trade history for each community and the time is from June $25^{\text {th }}, 2015$ to Dec. $9^{\text {th }}, 2015$. The data contains the number of apartments, the number of register apartments, the number and amount of purchase in the X platform. At present, the platform only offers service for laundry, tourism, and supermarket. This paper is to analyze the sale status in several communities in
Beijing. According to the results of the analysis, it is expected to give some advices on the business direction, sale strategies and future development. Hopefully, the analysis results can help to do precision marketing for every community, and lead more income for the $\mathrm{X}$ e-commerce platform.

\section{Hierarchical Clustering}

Hierarchical clustering essentially consists of progressively organizing all of the candidate objects into clusters comprising mutually similar objects as determined by some measure of inter-object and inter-cluster similarity, proceeding in succession from the formation of small clusters containing just two objects to large clusters containing many objects. It is characteristic of this procedure that the clusters formed in each step can be graphically displayed in tree diagrams referred to as dendrograms. Hierarchical clustering is widely used as it visuality, but it is less efficient for large observations. In this paper, the 11 communities are clustered into several groups and only 7 variables are used. The 7 variables are the total number of apartments, total number and amount of supermarket, laundry and tourism sales. The original dataset has 1815 observations, but are summed to 11 rows and 7 columns, and each row resents a community. The dataset is suitable for hierarchical clustering method. The data are 
transformed by z-score standardized before clustering.

By clustering, the 11 communities are grouped into several clusters, and the analysis about these clusters is then performed.

\section{Descriptive Study}

Figure 1 shows the spatial distribution of 11 communities in Beijing. The name and the apartment number of each community are marked in the map. In the map, the size and color of each community is proportional to its apartment number. It can be seen from the map that communities are mainly in Beijing suburban areas. In terms of prices, TN one and Original Villa are in the most expensive areas; while Mount Hope, M Chantilly, X Chantilly, and S Paridise are in the cheapest areas. The other communities are in the middle scale. Original Villa is the villa community and the others are apartment community.

\section{Spatial Distribution of 11 Communities in Beijing}

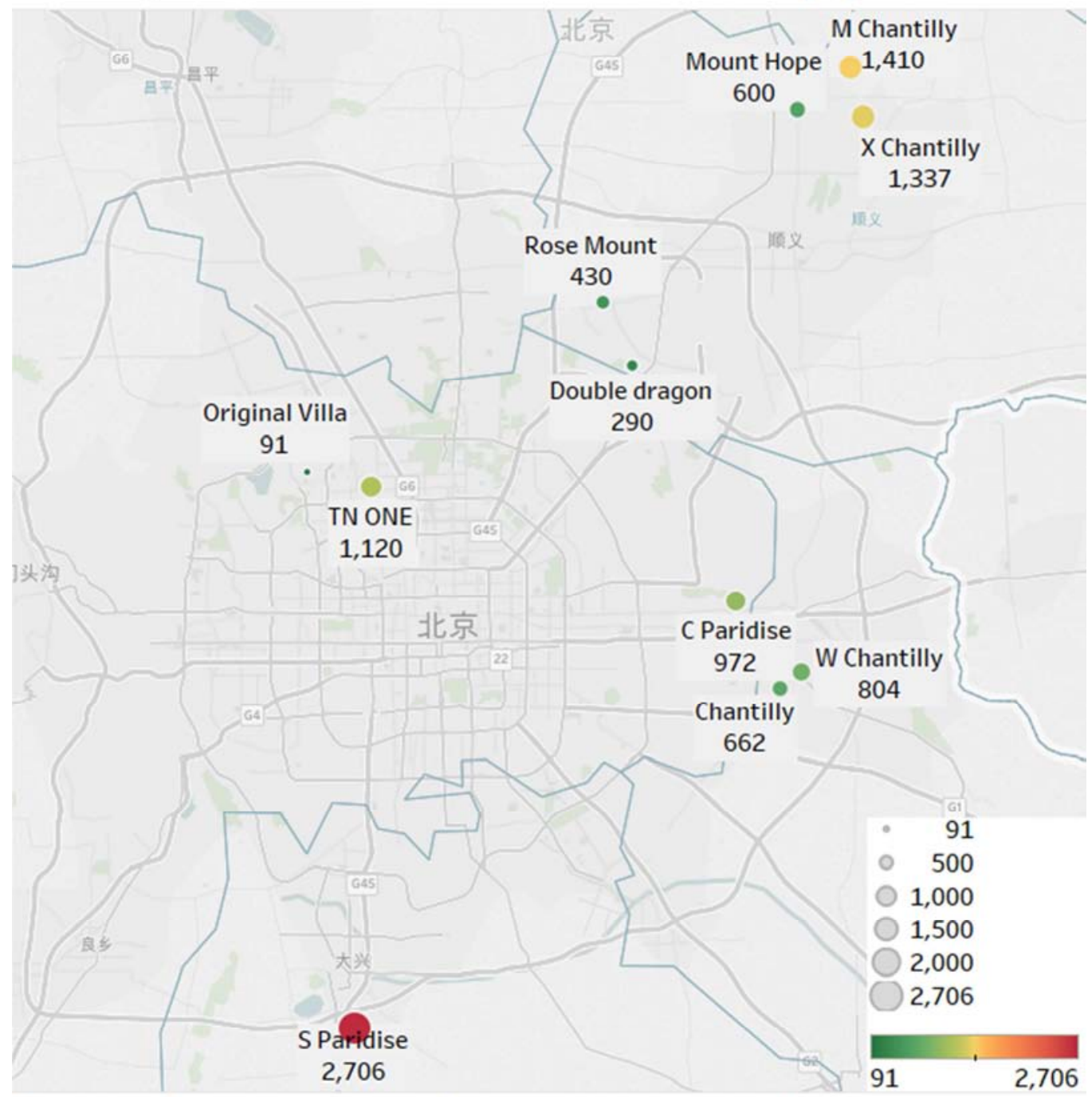

The name and the apartment number of each community are marked in the map.

Figure 1. The spatial distribution of 11 communities in Beijing. The name and the apartment number of each community are marked in the map. The size and color of each community is proportional to its apartment number.

The accumulative register persons in each community are shown in Figure 2. Each color indicates each community. The name and the apartment number of each community are also marked in the figure. Figure 2 displays that the number of register persons increase as time increase. The communities with larger apartments often have larger register persons. In the beginning time of June and July, most communities have the fastest increase rate, and the growth rates gradually decrease. In the end of September, the increase rate of most communities is very low and the lines in the Figure 2 keep even then. 


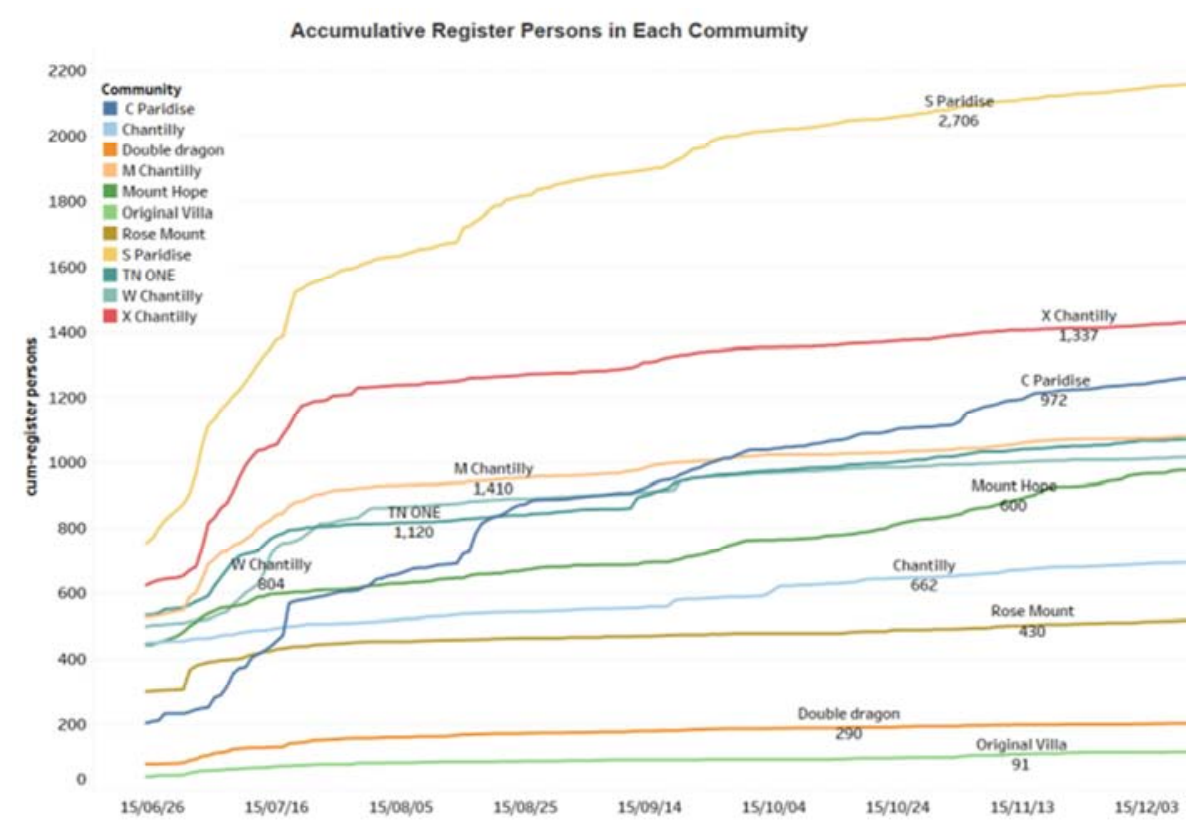

Figure 2. The accumulative register persons in each community. Each color indicates each community. The name and the apartment number of each community are also marked in the figure.

Accumulative register rate of apartments in each community is the ratio between registered apartment number and total apartment number in the community. Every person can register in X platform, but only the apartment owners can register their apartments. The owners can get more extra service if they register their apartments. Figure 3 shows the accumulative register rate of apartments in each community. Each color indicates each community. The name and the apartment number of each community are also marked in the figure. The increase trend in the Figure 3 is very similar to the trend in the Figure 2, but the gaps among the lines in Figure 2 are far less than those in Figure 3. The order of each community in apartment register rate is different from that in Figure 2 of register persons. For example, Community Chantilly has lowest apartment register rate but have median register persons. Community S Paridise have largest register persons in Figure 2 but have median apartment register rate. The order difference between Figure 2 and Figure 3 is because of the different measurements

Accumulative Register Rate of Apartments in Each Commumity

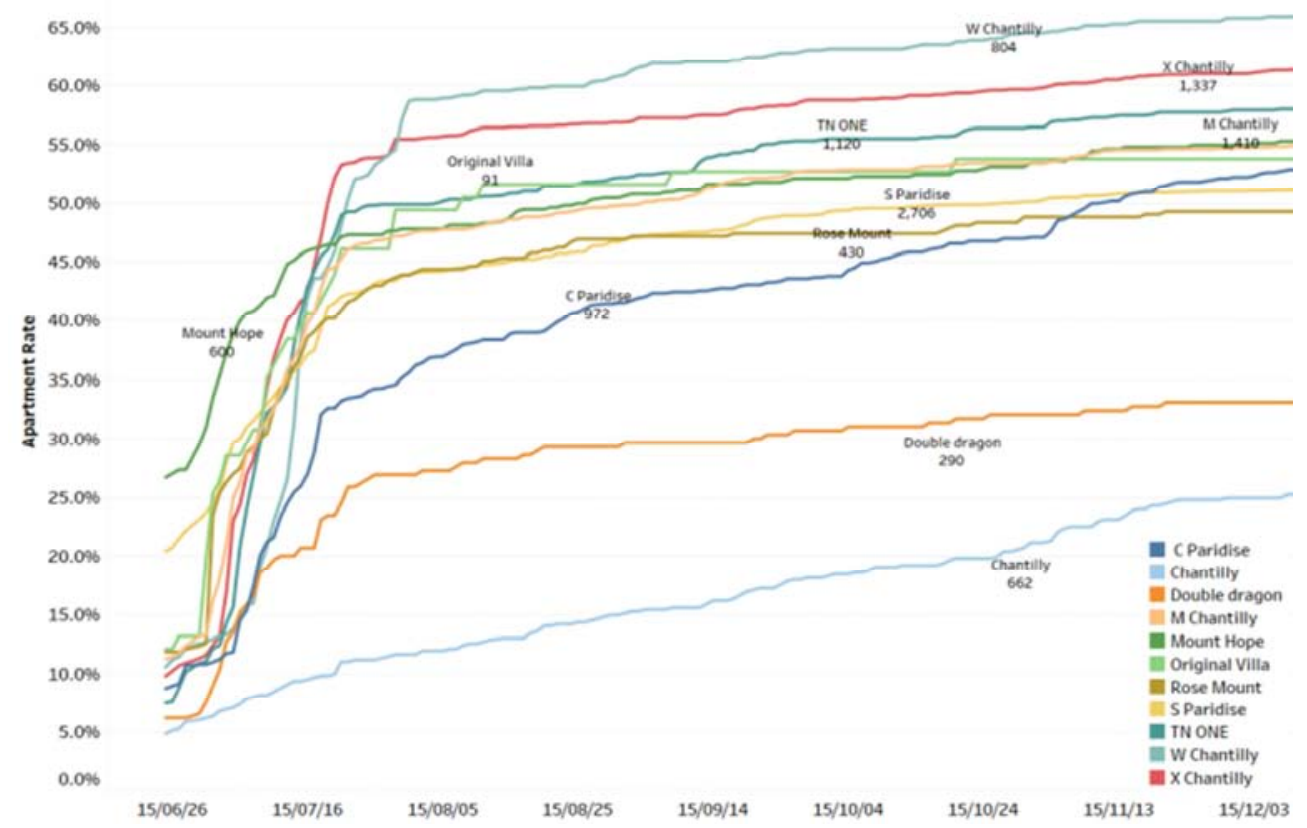

Figure 3. The accumulative register rate of apartments in each community. Each color indicates each community. The name and the apartment number of each community are also marked in the figure. 
The sale amounts of supermarket, laundry and tourism for each community are shown in Figure 4, Figure 5 and Figure 6 respectively. In the Figure 4, Rose Mount has the highest supermarket consumption, and the original villa has the least amount. In the figure 1, the number of apartments in each community is shown, and the order of sale amount in Figure 4 is a little different from that in Figure 1. In general, communities with high apartments often have high consumption on supermarket, as more people have more daily necessities. However, S Pardise has most apartments but has fewer sale amount. The communities of M Paridise and $\mathrm{C}$ Paridise also have similar problem. The $\mathrm{X}$ platform should put much resource in these communities to get more customers and sale amounts. The orders of laundry sales in Figure 5 are similar with the order in Figure 4. The interesting things are found that no laundry sales in the communities of Double dragon, Original Villa and S paradise. For the Original Villa, it may because the residents are all rich people and they often have expensive clothing. They prefer to do laundry in their familiar shops. But for the other no laundry communities, the $X$ platform should invest much resource on advertising and service. Figure 6 shows the sale amount of tourism in each community. The new things are found that Original Villa has the highest consumption on tourism. This is because that tourism is a little bit of luxury leisure and rich residents in that community often have mood and money to enjoy the tourism.

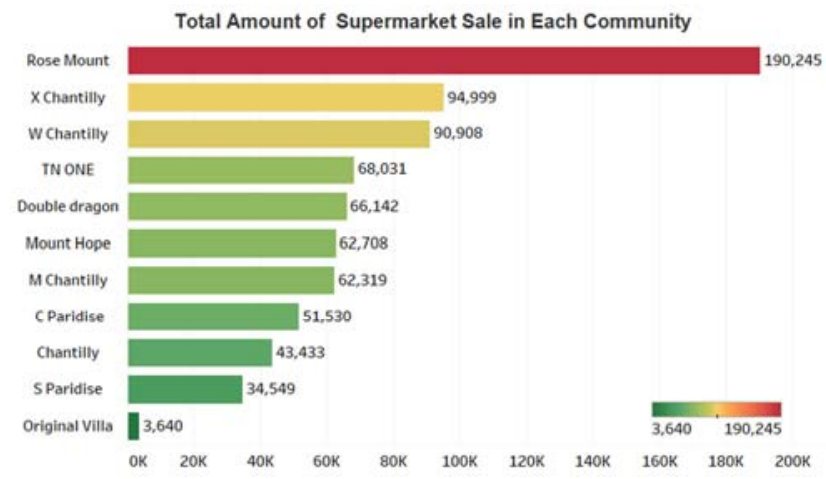

Figure 4. Total amount of supermarket sale in each community, and the sale amount is marked in plot. The length and color of each bar is proportional to its supermarket sale amount.

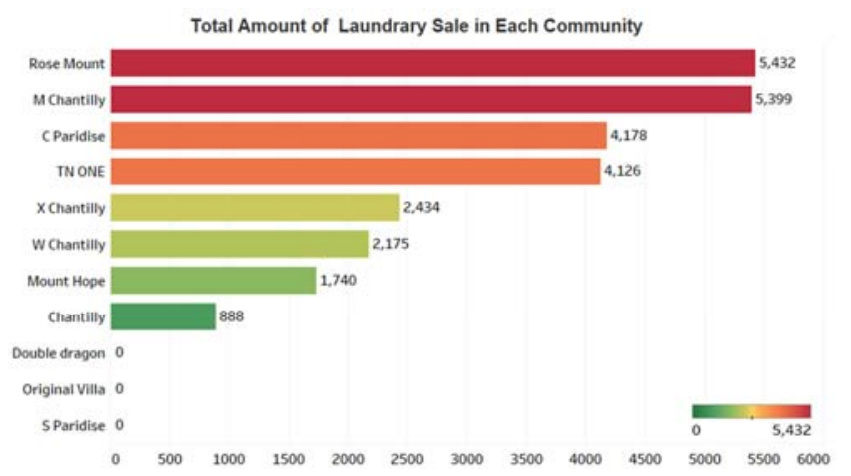

Figure 5. Total amount of laundry sale in each community, and the sale amount is marked in plot. The length and color of each bar is proportional to its laundry sale amount.

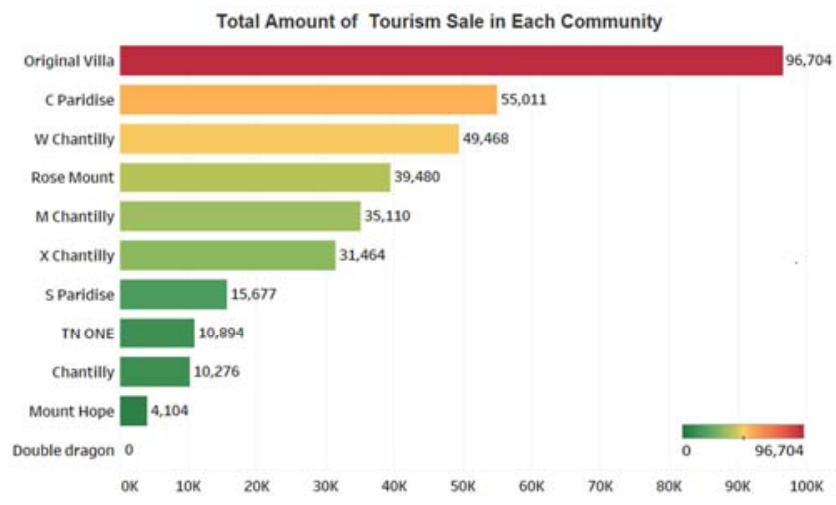

Figure 6. Total amount of tourism sale in each community, and the sale amount is marked in plot. The length and color of each bar is proportional to its tourism sale amount.

\section{Clustering Result}

After the Hierarchical Clustering, the tree-diagram are shown in Figure 7, and it demonstrate how the communities are grouped into small groups in detail.

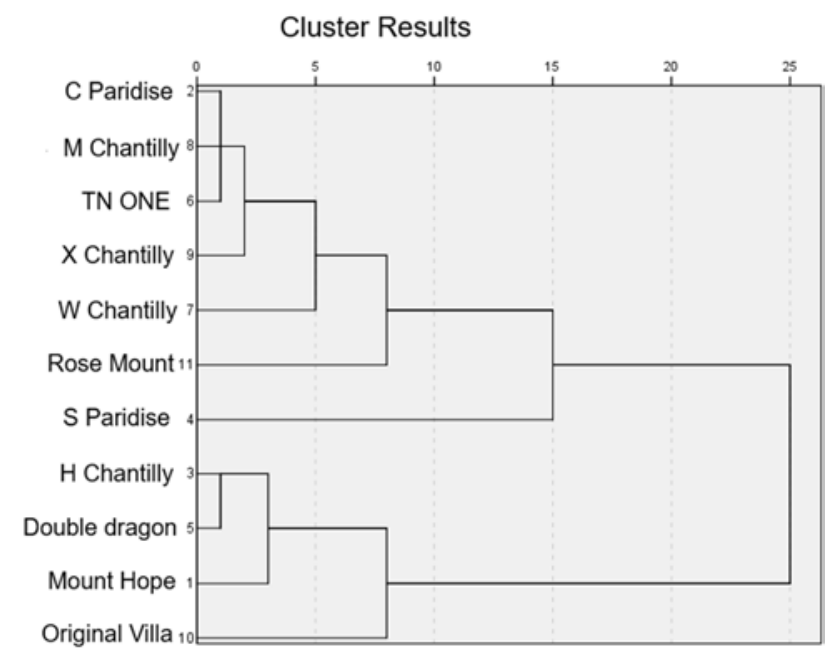

Figure 7. The process of the segmentation.

From the figure 7 and based on the analysis on last section, the 11 communities are grouped into 4 sub-groups. Cluster 1 are the communities of C Paridise, M Chantilly, TN One, X Chantily, W Chantilly and Rose Mount; Cluster 2 includes S Paridise only; Cluster 3 contains H Chantilly, Double dragon, Mount Hope; Cluster 4 has Original Villa only.

From the results in Figure 1-6, the communities in Cluster 1 often have large register persons and apartments. The residential incomes in these communities are median and they pay much on their daily necessities. For these communities, the $\mathrm{X}$ platform should advertise much on practical products to these communities.

For Cluster 2, it has S Paridise community only. This community is a very community but have fewer register persons and apartments. The further check with S Paridise shows that this community is a new community and Many residents have not lived in their apartments. The residential 
incomes in this communities are also not high, and the $\mathrm{X}$ platform should also advertise much on practical products to them.

For Cluster 3, the residential incomes in these communities are relative high, and the $\mathrm{X}$ platform should offer good products and services to the residents. For the Cluster 4, it has Original Villa only, and residential incomes in this community are relative high. Residents have high quality lifestyle, and the $\mathrm{X}$ platform should advertise much on luxury products and services.

\section{Conclusions}

This paper analyses the sale status of the $\mathrm{X}$ e-commerce platform. This platform runs their business in 11 communities in Beijing, and the total number of apartments, total number and amount of supermarket, laundry and tourism sales are described. The accumulate number of register persons and apartment register rates in most communities increase as time, and have fast increase in the beginning time, but gradually keep even. Based on the total number of apartments, total number and amount of supermarket, laundry and tourism sales, 11 communities are grouped into 4 cluster by Hierarchical Clustering. Based on the features of communities in each cluster, the profile of each cluster is analyzed and some suggestions for the $\mathrm{X}$ platform are given. The $\mathrm{X}$ platform should advertise much on practical products and services to communities in cluster 1 and cluster 2, and offer good products and services to the residents in cluster 3, while advertise much on luxury products and services for the residents in cluster 4 . This paper does a simple description and analysis on the data from $\mathrm{X}$ platform, and the results in this paper can be a reference to X platform. Hopefully, the results can be used to modify the strategies of the $\mathrm{X}$ platform for future development.

\section{Acknowledgements}

This paper is funded by the project of National Natural Science Fund, Logistics distribution of artificial order picking random process model analysis and research (Project number: 71371033); and funded by intelligent logistics system Beijing Key Laboratory (No.BZ0211) and Beijing Intelligent Logistics System Collaborative Innovation Center; and funded by scientific-research bases---Science \& Technology Innovation Platform---Modern logistics information and control technology research (Project number: PXM2015_014214_000001); University Cultivation Fund Project of 2014-Research on Congestion Model and algorithm of picking system in distribution center (0541502703).

\section{References}

[1] Carlos Pestana Barros, Zhongfei Chen, Luis A. Gil-Alana. Housing sales in urban Beijing[J]. Applied Economics, 2012, 44(34):4495-4504.
[2] Chen D, University B U. Empirical Study on Logistics Service and Willingness-to-Pay in E-commerce Environment: Taking Sales of Fresh Produce in Beijing as Example [J]. Logistics Technology, 2013.

[3] Cao R. Analysis of the creation process of the bid-winning scenario__ on YangtzeRiver Pharmaceutical Group, Beijing Branch Sales department building.[J]. Journal of North China Institute of Science \& Technology, 2004.

[4] Chang-Gui M A. An Analysis of the English (or Letter) Names of the on-sale Buildings in Beijing[J]. Journal of Xiaogan University, 2006.

[5] Christopher C. Yang, Xuning Tang, Qizhi Dai, et al. Identifying Implicit and Explicit Relationships through User Activities in Social Media [J]. International Journal of Electronic Commerce, 2013, 18(2):73-96.

[6] Derpsch R, Friedrich T, Kassam A, et al. Current status of adoption of no-till farming in the world and some of its main benefits.[J]. International Journal of Agricultural \& Biological Engineering, 2010, 3(1):1-25.

[7] Etsuko Kusukawa, Shinji Masui, Ikuo Arizono. Impact of E-Commerce Environment on Selection of Sales Methods Considering Delivery Lead Time of Goods [M]// Human Interface and the Management of Information. Interacting in Information Environments. Springer Berlin Heidelberg, 2007:929-938.

[8] Hao C X. Statistical Analysis of the Economic Level of Beijing [J]. Journal of Anhui Agricultural Sciences, 2010.

[9] Hilderman R J, Hamilton H J. Measuring the interestingness of discovered knowledge: A principled approach [J]. Intelligent Data Analysis, 2003, 7(4):347-382.

[10] Hu X, Kumar A. Case---Beijing Opera Mask Sales in Four Cities in the United States [J]. Informs Transactions on Education, 2013, 13(3):145-151.

[11] Liu J X, Zhao H F. Research on the development status, countermeasures and direct sales models of agricultural products in Beijing[J]. Journal of Agricultural University of Hebei, 2013.

[12] Li G, Liu M, Guan X, et al. Collaborative Policy of the Supply-Hub for Assemble-to-Order Systems with Delivery Uncertainty[J]. Discrete Dynamics in Nature \& Society, 2014, 2014(2):1-10.

[13] Ming-Sho H. From Resistance to Accommodation: Taiwanese Working Class in the Early Postwar Era (1945-55)[J]. Journal of Contemporary Asia, 2014, 44(3):479-499.

[14] News I, News A, News F, et al. Lentuo and Bitauto Establish JV with UXIN to Build Online-to-Offline platform for High-end Pre-owned Cars in China[J].

[15] Pratschke J, Morlicchio E. Social Polarisation, the Labour Market and Economic Restructuring in Europe: An Urban Perspective [J]. Urban Studies, 2012, 49(9):1891-1907.

[16] Qiu Y. Quantitative Analysis of the Trend in Retail Sales of Consumer Goods in Beijing [J]. Journal of Beijing Technology \& Business University, 2008.

[17] Shi W Z, Wang L W, Zhao Z G, et al. Analysis and Comparison of Drug Sales between Second-grade Hospitals and Community Hospitals in Beijing from 2009 to 2012[J]. China Pharmacy, 2014. 
[18] Schwab K. Connected world: transforming travel, transportation and supply chains [J]. Forecasting, 2013.

[19] Sacco G M, Tzitzikas Y, Sacco G M, et al. Dynamic Taxonomies and Faceted Search [J]. Journal of Laryngology \& Otology, 2012, 20(12):85-86.

[20] Trotter D L, Wang L. A Descriptive Analysis of the Contents and Origins of Research on China Marketing in English [J]. International Journal of China Marketing, 2012.

[21] Wang H F, Qiu J X, Breuste J, et al. Variations of urban greenness across urban structural units in Beijing, China [J]. Urban Forestry \& Urban Greening, 2013, 12(4):554-561.

[22] Wang Q L, Pharmacy D O, Hospital B F, et al. The analysis of application of antihypertensive drugs in a hospital during 2010 2013「J|. Journal of Clinical \& Experimental Medicine, 2014, 5(7):136-136.
[23] Yeung J. The Song of the Earth: An Analysis of Two Interlingual and Intersemiotic Translations [J]. Medical Education, 1981, 15(6):414-21.

[24] Zhang X H. Analysis on Usage of TCM Decoction Pieces in Liangxiang Hospital in Fangshan District of Beijing During 2011-2014[J]. Chinese Journal of Information on Traditional Chinese Medicine, 2015.

[25] Zhao AP, Ge X S. Analysis of Agricultural Origin in Wholesale Food Market in Beijing [J]. 2009.

[26] Zhang Y Y, Yu X Q. Probability feature of element transition and internal inverse $\mathrm{P}$ \&rho;-sets $[\mathrm{J}]$. Polski Tygodnik Lekarski, 1954, 8(51):1721-6.

[27] Zhang J, Ling-Shan M A. Analysis of the Publishing Website Performance on Internet Based on Flow Data $\lceil J\rceil$. Journal of Beijing Institute of Graphic Communication, 2012. 